\title{
Cancer Variant Interpretation Group UK (CanVIG-UK): an exemplar national subspecialty multidisciplinary network
}

\author{
Alice Garrett (1) , ${ }^{1}$ Alison Callaway, ${ }^{2,3}$ Miranda Durkie, ${ }^{4}$ Cankut Cubuk, ${ }^{1,5}$ \\ Mary Alikian, ${ }^{1}$ George J Burghel (0), ${ }^{6}$ Rachel Robinson, ${ }^{7}$ Louise Izatt, $^{8}$ \\ Sabrina Talukdar, ${ }^{9}$ Lucy Side, ${ }^{10}$ Treena Cranston, ${ }^{11}$ Sheila Palmer-Smith, ${ }^{12}$ \\ Diana Baralle, ${ }^{13}$ Ian R Berry (1) ${ }^{7}$ James Drummond, ${ }^{14}$ Andrew J Wallace, ${ }^{6}$ \\ Gail Norbury, ${ }^{15}$ Diana M Eccles $10,{ }^{13}$ Sian Ellard, ${ }^{16}$ Fiona Lalloo, ${ }^{6}$ \\ D Gareth Evans (i) ${ }^{6,17}$ Emma Woodward, ${ }^{6,17}$ Marc Tischkowitz, ${ }^{18}$ Helen Hanson, ${ }^{1,9}$ \\ Clare Turnbull $\mathbb{C}^{1,1,19}$ On behalf of the CanVIG-UK
}

- Additional material is published online only. To view, please visit the journal online (http://dx.doi.org/10.1136/ jmedgenet-2019-106759).

For numbered affiliations see end of article.

Correspondence to Dr Clare Turnbull, Division of Genetics and Epidemiology, Institute of Cancer Research, Sutton SM2 5NG, UK: clare.turnbull@icr.ac.uk

$A G, A C$ and $M D$ contributed equally.

Received 4 December 2019 Revised 6 February 2020 Accepted 7 February 2020 Published Online First 13 March 2020

\section{ABSTRACT}

Advances in technology have led to a massive expansion in the capacity for genomic analysis, with a commensurate fall in costs. The clinical indications for genomic testing have evolved markedly; the volume of clinical sequencing has increased dramatically; and the range of clinical professionals involved in the process has broadened. There is general acceptance that our early dichotomous paradigms of variants being pathogenic-high risk and benign-no risk are overly simplistic. There is increasing recognition that the clinical interpretation of genomic data requires significant expertise in disease-gene-variant associations specific to each disease area. Inaccurate interpretation can lead to clinical mismanagement, inconsistent information within families and misdirection of resources. It is for this reason that 'national subspecialist multidisciplinary meetings' (MDMs) for genomic interpretation have been articulated as key for the new NHS Genomic Medicine Service, of which Cancer Variant Interpretation Group UK (CanVIGUK) is an early exemplar. CanVIG-UK was established in 2017 and now has > 100 UK members, including at least one clinical diagnostic scientist and one clinical cancer geneticist from each of the 25 regional molecular genetics laboratories of the UK and Ireland. Through CanVIG-UK, we have established national consensus around variant interpretation for cancer susceptibility genes via monthly national teleconferenced MDMs and collaborative data sharing using a secure online portal. We describe here the activities of CanVIG-UK, including exemplar outputs and feedback from the membership.

\section{BACKGROUND Clinical utility of cancer susceptibility genes (CSGs)} employer(s)) 2020. Re-use permitted under CC BY. Published by BMJ.

To cite: Garrett $A$, Callaway A, Durkie $M$, et al. $J$ Med Genet

2020;57:829-834.
Analysis of germline (constitutional) variants in CSGs constitutes approximately one-quarter of activity in NHS Molecular Diagnostic Laboratories in England. ${ }^{1}$ Following identification of a pathogenic variant $(\mathrm{PV})$ in a CSG, incidence of/mortality from future cancers may be mitigated via (1) risk-reducing surgery (eg, mastectomy, gastrectomy, salpingo-ophorectomy and colectomy); (2) chemoprevention; (3) intensive screening; and (4) lifestyle modification. ${ }^{2}$ Family members negative for the familial CSG-PV can be spared anxiety and unnecessary screening. Many CSGs are associated with a pattern of cancer risk that is late-onset, variably penetrant and of autosomal dominant inheritance. PV-positive family members identified via cascade screening are often distributed across disparate genomics services.

Erroneous interpretation of CSG variant pathogenicity can therefore result in (1) discordant management within families, (2) serious clinical consequences for individuals and (3) misdirection at population level of resources for screening and prevention. $^{3-5}$ Increasingly, CSG-PVs are used as predictive biomarkers to inform cancer therapy. For all these reasons, robust, rapid, accurate variant analysis and interpretation of disease risk are critical to effective delivery of germline cancer genetics and improving outcomes for patients.

\section{Evolving landscape of variant interpretation in germline cancer genetics}

In the late 1990s, within a few years of identification of the relevant genes, laboratory analysis of CSGs became available in the UK via family cancer clinics. $^{2}$ If the cancer phenotype ascribed to the gene matched that found in the proband/family under study, with little additional evidence, a rare variant would often be labelled as pathogenic and thus causative. ${ }^{6}$ Subsequent large-scale population sequencing studies have revealed the degree of innocuous variation present in the human genome (and indeed in disease-associated genes) and 'downgrading' of many erroneously labelled PVs has been required. $^{7}$ An era of caution followed, with much greater recourse to labelling of variants as 'variants of uncertain significance' (VUS/VOUS). However, lack of systems for sharing new evidence has meant that many families have spent years in limbo with their 'VUS', even when data had long been available 
by which classification of their variant could be downgraded or upgraded.

Sharing of clinical variant data was somewhat improved with the advent of locus-specific databases (LSDs), such as Breast Cancer Information Core and Leiden Open Variant Databases. ${ }^{8-11}$ However, the curation of clinical and molecular data in LSDs often remains suboptimal, with (1) erroneous nomenclature, (2) duplication of entries and (3) use of differing classification systems resulting in contradictory assignations. ${ }^{12}$

Using Myriad Genetics data from 70000 genetic tests for hereditary breast and ovarian cancer, in 2007, Easton and colleagues published a landmark multifactorial analysis through which 'odds of causality' were mathematically generated for 1433 variants using clinical, pedigree and allelic data. ${ }^{13}$ In 2008 , International Agency for Research on Cancer (IARC) collaborators published the first formal five point variant interpretation system for CSGs, which included numeric thresholds for the probability of pathogenicity. ${ }^{14}$ Expert cancer susceptibility consortia such as the Evidence-based Network for the Interpretation of Germline Mutant Alleles (ENIGMA) and the International Society for Gastrointestinal Hereditary Tumours (InSIGHT) further evolved these multifactorial variant classification systems to incorporate tumour phenotype and in silico predictions. ${ }^{15-17}$ However, ENIGMA/InSIGHT approaches require statistical genetic-epidemiological analyses of large curated data series and are not reproducible by an individual diagnostic laboratory seeking to classify in a clinically relevant timescale a newly identified variant.

In 2015, the American College of Medical Geneticists (ACMG) published a variant interpretation framework enabling the combination by a diagnostic laboratory of disparate evidence sources for a newly identified genomic variant. ${ }^{18}$ The ACMG framework has subsequently been further evolved under the auspices of ClinGen, including (1) specification for how it is applied to particular genes and/or diseases (including TP53, CDH1 and PTEN); (2) deeper specification of particular criteria (eg, functional assays); and (3) exposition of the underpinning Bayesian model. ${ }^{19-23}$

Coordinated national UK approaches in variant interpretation In 2016, with endorsement from NHS England and Health Education England, it was agreed formally by the UK Association of Clinical Genomic Science (UK-ACGS) to adopt the ACMG variant interpretation framework. ${ }^{24} 25$ The UK-ACGS established national groups for rare disease, germline cancer genetics, cardiac disease and hypercholesterolaemia to develop and disseminate practice in the application of the ACMG variant interpretation framework. ${ }^{24}$ In parallel was recognition within the NHS Genomic Medicine Service of the need for national subspecialist genomics MDMs. ${ }^{26} 27$ In response to these dual recommendations, Cancer Variant Interpretation Group UK (CanVIG-UK) was initiated in 2017.

\section{CANCER VARIANT INTERPRETATION GROUP UK}

The purpose of CanVIG-UK is to advance outcomes for patients by improving the accuracy and consistency of interpretation of variants in CSGs across the UK clinical genetics and molecular diagnostic laboratory communities (hereafter termed the UK clinical-laboratory community). We aim to progress this goal by advancing six objectives (see box 1).

\section{Creation of a national multidisciplinary professional network and regular forum}

CanVIG-UK has grown to now include $>100$ members, incorporating clinical and laboratory representation from each of the

\section{Box 1 CanVIG Objectives}

The purpose of Cancer Variant Interpretation Group UK (CanVIG-UK) is to advance outcomes for patients by improving the accuracy and consistency of interpretation of variants in Cancer Susceptibility genes across the UK clinical-laboratory community. We have six specific objectives:

1. Creation of a national multidisciplinary professional network and regular forum.

2. Training and education.

3. Detailed specification for germline cancer genetics of the UKACGS Best Practice Guidelines for Variant Interpretation.

4. Ratification of additional guidance in germline cancer genetics relevant to the UK clinical-laboratory community.

5. Development of an online platform to facilitate information sharing and variant interpretation within the UK clinicallaboratory community.

6. UK contribution to international variant interpretation endeavours.

25 Molecular Diagnostic Laboratories and Clinical Genetics Services of the UK (NHS) and Ireland (see collaborators). This group comprises roughly equal proportions of clinical scientists and clinical geneticists, with two-thirds working exclusively or predominantly in cancer genetics (figure 1):

- The monthly teleconferenced MDM provides a forum to which problematic variants/cases are submitted. The variants submitted to the monthly variant surgery are circulated 1 week in advance. CanVIG-UK members are asked (1) to ascertain whether additional cases and/or laboratory data exist locally and (2) to undertake local, independent classification of the variant. The relevant clinical and laboratory data are presented by the nominating laboratory. This is followed by input of any additional information by the broader CanVIG-UK group and a discussion regarding the legitimacy of the ACMG criteria awarded. Following this discussion and an online postdiscussion poll, a consensus CanVIG classification is generated (see online supplementary table 1). A detailed date-stamped CanVIG variant summary sheet is generated (see online supplementary appendix 2), which is circulated by email, uploaded to the CanVar-UK portal and submitted to ClinVar.

- The CanVIG-UK network is active throughout the month via the email forum, through which urgent queries can be debated and addressed.

\section{Training and education}

The discussion of cases at the MDM also provides valuable education for the clinical-laboratory community regarding application of the ACMG framework and the vagaries of the evidence sources used (see figure 2). Additionally, through CanVIG-UK, we have supported training of the broader UK genetics and oncology communities in variant interpretation for CSGs.

\section{Detailed specification for germline cancer genetics of the UK- ACGS Best Practice Guidelines for Variant Interpretation}

On behalf of the UK-ACGS, the rare disease variant interpretation group has generated and updates annually a highly detailed specification of the ACMG variant interpretation framework . ${ }^{24}$ In cancer susceptibility, we typically observe variants relating to late-onset, common phenotypes. De novo and biallelic 

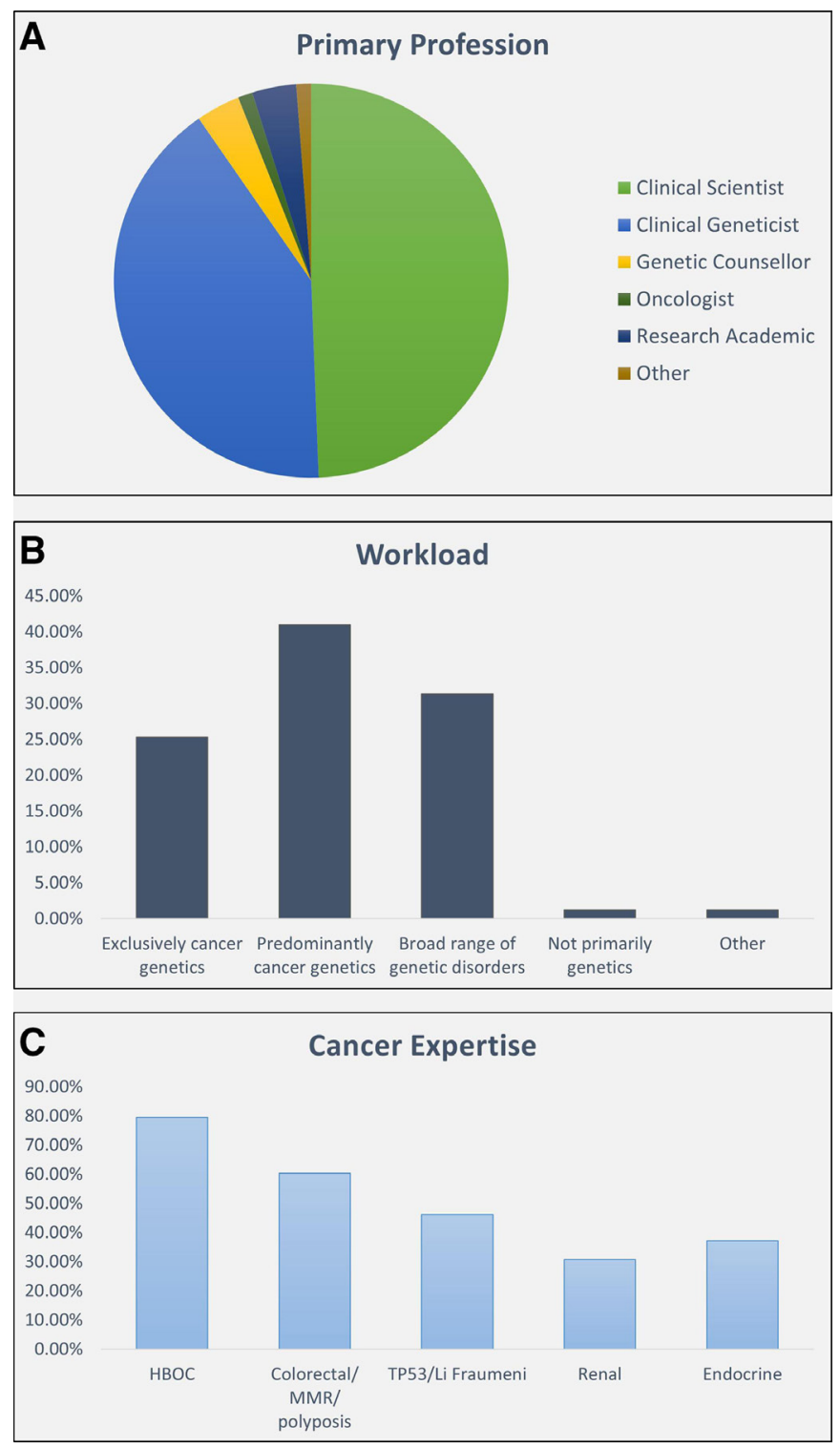

Figure 1 Overview of the CanVIG-UK membership profile (survey of CanVIG-UK members, performed on 29 October 2019, return rate 83/103 (81\%). HBOC, hereditary breast and ovarian cancer; MMR, mismatch repair. CanVIG-UK, Cancer Variant Interpretation Group UK.

paradigms are infrequent. We are typically much more reliant on variant frequency from case series and functional assays. Thus, an important remit for CanVIG-UK has been to develop a detailed specification of the UK-ACGS framework for these types of evidence to be used for CSG variant interpretation (see online supplementary appendix 1).

\section{Ratification of additional guidance in germline cancer genetics relevant to the UK clinical-laboratory community}

Historically, the first presentation to the family cancer clinic was typically an unaffected individual, concerned by a significant family history. Increasingly, genetic analysis is now performed as part of routine work-up at cancer diagnosis, either through analysis of a germline sample or through therapeutically motivated molecular analysis of the tumour. In both contexts, (1) focused testing of one or two genes has often been superseded by broad 'cancer panels' containing dozens or hundreds of genes; (2) patients may be unselected for family history; and (3) analysis and reporting in a tight time frame is typically required. A number of challenging issues have emerged, including

1. Categorisation and management of reduced penetrance variants in high-penetrance genes.

2. Variant interpretation and clinical management for moderatepenetrance genes.

3. Adaptation of variant interpretation and risk for different contexts of ascertainment.

4. Inference of germline findings from tumour-only sequencing.

While germane across genomics, consideration of these issues has become pressing within germline cancer genetics. Benefitting from its regular forum, multidisciplinary membership and alignment with both UK-ACGS and the UK Cancer Genetics Group (UK-CGG), we have used the CanVIG-UK monthly forum to evolve UK national multidisciplinary approaches on such issues (see online supplementary appendix 3).

\section{Development of an online platform to facilitate information sharing and variant interpretation within the UK clinical- laboratory community}

In germline cancer genetics, enrichment in cases (especially 'strong families') is one of the most valuable clinical observations indicating variant pathogenicity. However, to date, we have struggled to quantify such observations on account of (1) failure to aggregate national data from distributed laboratories and (2) lack of a robust denominator.

In a collaborative venture between Public Health England (PHE) and the national network of molecular diagnostic laboratories, data from molecular testing of CSGs have been submitted via a pseudonymisation portal to the secure National Cancer Registration and Analysis Service (NCRAS) data environment of PHE. ${ }^{28}$ The national variant totals (numerator and denominator) are then shared by CanVIG-UK with the UK clinical-laboratory community via our online data system CanVar-UK (http://www. canvaruk.org/).

CanVar-UK provides additional annotations for 1008643 variants from 95 CSGs. It includes variant-level annotations from LSDs (case counts), functional assays, splicing assays and multifactorial analyses for selected genes. Accessible only to registered CanVIG-UK clinical-laboratory users is a community area for sharing non-identifiable variant-level data, such as local classifications, comments/notes, uploaded documents and results from local laboratory assays (eg, RNA analyses of potential splicing variants).

\section{UK contribution to international variant interpretation endeavours}

CanVIG-UK is an effective conduit between the UK clinicallaboratory germline cancer genetics community and relevant international variant interpretation endeavours in several regards:

- First, there is representation at the international ClinGen SVI group from the leadership of the UK-ACGS rare disease variant interpretation group. The regular crosstalk between leadership of the UK groups enables appraisal of the ClinGen SVI group of emerging analyses and activity within CanVIG-UK and the UK clinical-laboratory cancer genetics community.

- Second, multiple members of CanVIG-UK are members of gene-specific international endeavours such as ENIGMA, InSIGHT and ClinGen expert groups.

- Third, data generated by CanVIG-UK data have contributed to collaborative international consortia analyses, for 


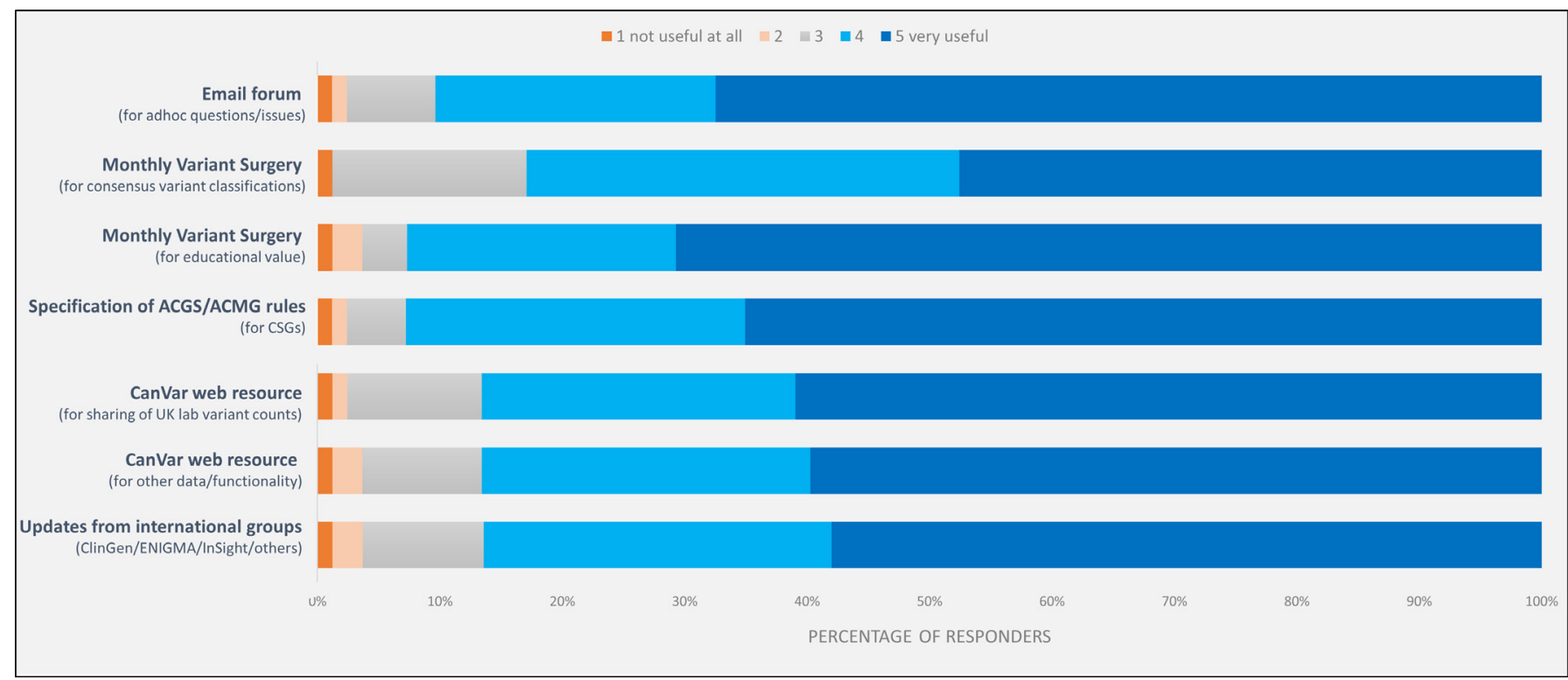

Figure 2 Perceived utility of CanVIG-UK activities regarding local practice in CSG variant interpretation of seven activities (5: very useful to 1: not useful; survey of CanVIG-UK members, performed on 29 October 2019, return rate 83/103 (81\%)). ACGS, Association of Clinical Genomic Science; ACMG, American College of Medical Geneticists; CanVIG-UK, Cancer Variant Interpretation Group UK; CSG, cancer susceptibility gene.

example, provision to ENIGMA of the summary PHE UK laboratory data on BRCA1/BRCA2 variants.

- Fourth, CanVIG-UK consensus classifications (and underpinning evidence) are shared via ClinVar. CanVIG-UK is the first UK organisation to submit clinical-laboratory variant classifications to ClinVar.

\section{Sustainability}

Maintenance of a national multidisciplinary network, coordination of a regular teleconferenced MDMs and development of a data system is only feasible via sustained support. The activities of CanVIG-UK are currently supported by a Cancer Research UK Catalyst Award (CanGene-CanVar, @CangeneCanvar, C61296/A27223).

\section{CONCLUSION}

CanVIG-UK is a multidisciplinary group comprising $>100$ clinical scientists and senior genetics clinicians working in germline cancer genetics, with representation from across the 25 NHS molecular diagnostic laboratories of the UK and Ireland. Through CanVIG-UK, the UK clinical-laboratory germline cancer genetics community have evolved:

1. An email forum for real-time consultation on problematic variants.

2. A monthly teleconferenced MDM for detailed review of challenging variants and cases.

3. A national programme of using secure submissions of frequency data from PHE.

4. An online data system (CanVar-UK) for sharing variant-level data both publicly and within a secure community region.

5. Detailed, consensus UK guidance for the interpretation of variants in CSGs.

6. Fruitful interactions with international CSG variant interpretation endeavours.

In summary, we propose CanVIG-UK as an exemplar National Subspecialty Multidisciplinary Genomics Network. In this era of rapid emergence of genomic knowledge, such networks are becoming increasingly important to optimise collaborative specialist case review, information sharing and education.

\section{Author affiliations}

${ }^{1}$ Division of Genetics and Epidemiology, Institute of Cancer Research, Sutton, UK

${ }^{2}$ Wessex Regional Genetics Laboratory, Salisbury Hospital NHS Foundation Trust, Salisbury, UK

${ }^{3}$ Human Genetics and Genomic Medicin, Faculty of Medicine, University of Southampton, Southampton, UK

${ }^{4}$ Sheffield Diagnostic Genetics Service, Sheffield Children's NHS Foundation Trust, Sheffield, UK

${ }^{5}$ William Harvey Research Institute, Queen Mary University of London, London, UK ${ }^{6}$ Manchester Centre for Genomic Medicine and NW Laboratory Genetics Hub, Manchester University NHS Foundation Trust, Manchester, UK

${ }^{7}$ Yorkshire Regional Genetics Service, Leeds Teaching Hospitals NHS Trust, Leeds, UK ${ }^{8}$ Department of Clinical Genetics, Guy's and Saint Thomas' NHS Foundation Trust, London, UK

${ }^{9}$ Department of Clinical Genetics, Saint George's University Hospitals NHS

Foundation Trust, London, UK

${ }^{10}$ Wessex Clinical Genetics Service, Princess Anne Hospital, Southampton, UK

${ }^{11}$ Oxford Molecular Genetics Laboratory, Churchill Hospital, Oxford, UK

${ }^{12}$ Institute of Medical Genetics, University Hospital of Wales, Cardiff, UK

${ }^{13}$ Faculty of Medicine, University of Southampton, Southampton, UK

${ }^{14}$ East Anglian Medical Genetics Service, Cambridge University Hospitals NHS

Foundation Trust, Cambridge, UK

${ }^{15}$ Regional Genetics Service, Guy's and Saint Thomas' NHS Foundation Trust, London, UK

${ }^{16}$ Department of Molecular Genetics, Royal Devon and Exeter NHS Foundation Trust, Exeter, UK

${ }^{17}$ Division of Evolution and Genomic Sciences, School of Biological Sciences, Faculty of Biology Medicine and Health, The University of Manchester, Manchester, UK

${ }^{18}$ Department of Medical Genetics, National Institute for Health, Research Cambridge Biomedical Research Centre, University of Cambridge, Cambridge, UK

${ }^{19}$ Cancer Genetics Unit, Royal Marsden NHS Foundation Trust, London, UK

Twitter George J Burghel @BurghelG, Ian R Berry @LaughingGenome, Emma Woodward @ER_Woodward and Clare Turnbull @clare_turnbull

Acknowledgements We acknowledge the contribution of Jenny Lord and Andrew Douglas to discussions regarding splicing guidance.

Collaborators CanVIG-UK: Stephen Abbs, Patrick Tarpey, Jonathan Bruty, James Drummond, James Whitworth, Anne Ramsay Bowden, Marc Tischowitz, Eamonn Maher (Cambridge University Hospitals NHS Foundation Trust); Shirley Heggarty, Sean Hegarty, Rosalind Martin, Peter Logan, Claire Byrne (Belfast Health and Social 
Care Trust); Yvonne Wallis, Samantha Butler, Rachel Hart, Lowri Hughes, Kim Reay, Kai-Ren Ong, Joanne Mason, lan Tomlinson (Birmingham Women's and Children's NHS Foundation Trust); Ian Frayling, Sheila Palmer-Smith, Julian Sampson, Alex Murray (Cardiff and Vale University Health Board); Munaza Ahmed, Louise Kiely, Louise Busby, Claire Brooks, Alison Taylor-Beadling, Ajith Kumar (Great Ormond Street Hospital for Children NHS Foundation Trust); Vishakha Tripathi, Mina Ryten, Louise Izatt, Anjana Kulkarni, Adam Shaw, Joanna Campbell (Guy's and St Thomas' NHS Foundation Trust); Huw Thomas (St. Mark's Hospital, Northwick Park Hospital, Harrow); Daniel Chubb, Mary Alikian, Cankut Cubuk (Institute of Cancer Research); Rachel Robinson, Brendan Mullaney, Julian Adlard (Leeds Teaching Hospitals NHS Trust); Karen-Lynn Greenhalgh, Emma Howard (Liverpool Women's NHS Foundation Trust); Virginia Clowes, Angela Brady (London North West University Healthcare NHS Trust); George Burghel, Emma Woodward, Philip T Smith, Jade L Harris, Naomi L Bowers, Claire L Hartley, Ronnie Wright, Gareth Evans, Fiona Lalloo, Andrew Wallace (Manchester University NHS Foundation Trust); John Burn, James Tellez, Sarah Mackenzie, Helen Powell (Newcastle Upon Tyne Hospitals NHS Foundation Trust); Stephen Tennant, Joanna Tolmie, Dawn O'Sullivan (NHS Grampian, Aberdeen); Rosemarie Davidson, Jonathan Grant, Daniel Stobo, Aisha Ansari (NHS Greater Glasgow \& Clyde); Jennie Murray, David Moore (NHS Lothian, Edinburgh); Rachael Tredwell, Joanne Field, Kirsty Bradshaw, Rachel Harrison (Nottingham University Hospital NHS Trust); Logan Walker (University of Otago, Christchurch, New Zealand); Trudi Mcdevitt, Marie Duff, Catherine Clabby (Our Lady's Children's Hospital, Crumlin, Dublin); Treena Cranston, Tina Bedenham, Evgenia Petrides, Lara Hawkes (Oxford University Hospitals NHS Foundation Trust); Fiona McRonald (Public Health England); Sian Ellard, Ruth Cleaver, Carole Brewer (Royal Devon And Exeter NHS Foundation Trust); Nick Woodwaer (Royal Free London NHS Foundation Trust); Stacey Daniels, Alison Callaway (Salisbury NHS Foundation Trust); Khalid Tobal, Shadi Albaba, Sarah Dell, Rodney Nyanhete, Richard Kirk, Mark Watson, Miranda Durkie, Jackie Cook, Hazel Clouston, Anne-Cecile Hogg (Sheffield Children's NHS Foundation Trust); Sabrina Talukdar, Lorraine Hawkes, Laura Cobbold, Kate Tatton-Brown, Helen Hanson, Katie Snape, Charlene Crosby, Ayaovi Hadonou Juan Carlos Del Rey Jimenez(St George's University Hospitals NHS Foundation Trust); Zoe Kemp, Terri Mcveigh, Clare Turnbull, Alice Garrett (The Royal Marsden NHS Foundation Trust); Cathal O'Brien (Trinity College Dublin, The University Of Dublin, Ireland); Laura Yarram, Kenneth Smith, Helen Williamson, Alan Donaldson (University Hospitals Bristol NHS Foundation Trust); Julian Barwell (University Hospitals of Leicester NHS Trust); Matilda Bradford (University Hospitals Plymouth NHS Trust); Lucy Side, Diana Eccles, Diana Baralle, Anneke Lucassen (University Hospital Southampton NHS Foundation Trust)

Contributors The manuscript was drafted by $\mathrm{CT}, \mathrm{AG}, \mathrm{AC}$ and $\mathrm{MD}$. All other authors contributed to the final manuscript.

Funding This work is supported by the CRUK Catalyst Award CanGene-CanVar (C61296/A27223). ERW and DGE are supported by the Manchester National Institute for Health Research Biomedical Research Centre (IS-BRC-1215- 20007).

Competing interests None declared.

Patient consent for publication Not required.

Provenance and peer review Not commissioned; externally peer reviewed.

Open access This is an open access article distributed in accordance with the Creative Commons Attribution 4.0 Unported (CC BY 4.0) license, which permits others to copy, redistribute, remix, transform and build upon this work for any purpose, provided the original work is properly cited, a link to the licence is given, and indication of whether changes were made. See: https://creativecommons.org/ licenses/by/4.0/.

\section{ORCID iDs}

Alice Garrett http://orcid.org/0000-0001-8942-283X

George J Burghel http://orcid.org/0000-0001-9360-8194

lan R Berry http://orcid.org/0000-0002-9710-4724

Diana M Eccles http://orcid.org/0000-0002-9935-3169

D Gareth Evans http://orcid.org/0000-0002-8482-5784

Clare Turnbull http://orcid.org/0000-0002-1734-5772

\section{REFERENCES}

1 Norbury G. Association of Clinical Genomic Science (ACGS) 2015-2016 Genetic Test Activity Audit2017.

2 Turnbull C, Sud A, Houlston RS. Cancer genetics, precision prevention and a call to action. Nat Genet 2018;50:1212-8.

3 Tandy-Connor S, Guiltinan J, Krempely K, LaDuca H, Reineke P, Gutierrez S, Gray P, Tippin Davis B. False-Positive results released by direct-to-consumer genetic tests highlight the importance of clinical confirmation testing for appropriate patient care. Genet Med 2018:20:1515-21.

4 Kilbride MK, Domchek SM, Bradbury AR. Ethical implications of direct-to-consumer hereditary cancer tests. JAMA Oncol 2018:4:1327-8.

5 . The Guardian, 2019. Available: https://www.theguardian.com/science/2019/jul/21/ senior-doctors-call-for-crackdown-on-home-genetic-testing-kits

6 Eccles DM, Mitchell G, Monteiro ANA, Schmutzler R, Couch FJ, Spurdle AB, GómezGarcía EB, ENIGMA Clinical Working Group. Brca1 and BRCA2 genetic testing-pitfalls and recommendations for managing variants of uncertain clinical significance. Ann Oncol 2015;26:2057-65.

7 Lek M, Karczewski KJ, Minikel EV, Samocha KE, Banks E, Fennell T, O’Donnell-Luria AH, Ware JS, Hill AJ, Cummings BB, Tukiainen T, Birnbaum DP, Kosmicki JA, Duncan LE, Estrada K, Zhao F, Zou J, Pierce-Hoffman E, Berghout J, Cooper DN, Deflaux N, DePristo M, Do R, Flannick J, Fromer M, Gauthier L, Goldstein J, Gupta N, Howrigan D, Kiezun A, Kurki MI, Moonshine AL, Natarajan P, Orozco L, Peloso GM, Poplin R, Rivas MA, Ruano-Rubio V, Rose SA, Ruderfer DM, Shakir K, Stenson PD, Stevens C, Thomas BP, Tiao G, Tusie-Luna MT, Weisburd B, Won H-H, Yu D, Altshuler DM, Ardissino D, Boehnke M, Danesh J, Donnelly S, Elosua R, Florez JC, Gabriel SB, Getz G, Glatt SJ, Hultman CM, Kathiresan S, Laakso M, McCarroll S, McCarthy MI, McGovern D, McPherson R, Neale BM, Palotie A, Purcell SM, Saleheen D, Scharf JM, Sklar P, Sullivan PF, Tuomilehto J, Tsuang MT, Watkins HC, Wilson JG, Daly MJ, MacArthur DG, Exome Aggregation Consortium. Analysis of protein-coding genetic variation in 60,706 humans. Nature 2016:536:285-91.

8 Pinard A, Salgado D, Desvignes J-P, Rai G, Hanna N, Arnaud P, Guien C, Martinez M, Faivre L, Jondeau G, Boileau C, Zaffran S, Béroud C, Collod-Béroud G. WES/WGS Reporting of Mutations from Cardiovascular "Actionable" Genes in Clinical Practice: A Key Role for UMD Knowledgebases in the Era of Big Databases. Hum Mutat 2016;37:1308-17.

9 Pinard A, Miltgen M, Blanchard A, Mathieu H, Desvignes J-P, Salgado D, Fabre A, Arnaud P, Barré L, Krahn M, Grandval P, Olschwang S, Zaffran S, Boileau C, Béroud C, Collod-Béroud G. Actionable genes, core databases, and locus-specific databases. Hum Mutat 2016:37:1299-307.

10 Szabo C, Masiello A, Ryan JF, Brody LC. The breast cancer information core: database design, structure, and scope. Hum Mutat 2000;16:123-31.

11 Fokkema IFAC, Taschner PEM, Schaafsma GCP, Celli J, Laros JFJ, den Dunnen JT. LOVD v.2.0: the next generation in gene variant databases. Hum Mutat 2011;32:557-63.

12 Greenblatt MS, Brody LC, Foulkes WD, Genuardi M, Hofstra RMW, Olivier M, Plon SE, Sijmons RH, Sinilnikova O, Spurdle AB, IARC Unclassified Genetic Variants Working Group. Locus-specific databases and recommendations to strengthen their contribution to the classification of variants in cancer susceptibility genes. Hum Mutat 2008:29:1273-81.

13 Easton DF, Deffenbaugh AM, Pruss D, Frye C, Wenstrup RJ, Allen-Brady K, Tavtigian SV, Monteiro ANA, Iversen ES, Couch FJ, Goldgar DE. A systematic genetic assessment of 1,433 sequence variants of unknown clinical significance in the BRCA1 and BRCA2 breast cancer-predisposition genes. Am J Hum Genet 2007;81:873-83.

14 Plon SE, Eccles DM, Easton D, Foulkes WD, Genuardi M, Greenblatt MS, Hogervorst FBL, Hoogerbrugge N, Spurdle AB, Tavtigian SV, IARC Unclassified Genetic Variants Working Group. Sequence variant classification and reporting: recommendations for improving the interpretation of cancer susceptibility genetic test results. Hum Mutat 2008:29:1282-91.

15 Spurdle AB, Healey S, Devereau A, Hogervorst FBL, Monteiro ANA, Nathanson KL, Radice P, Stoppa-Lyonnet D, Tavtigian S, Wappenschmidt B, Couch FJ, Goldgar DE, ENIGMA. ENIGMA-evidence-based network for the interpretation of germline mutant alleles: an international initiative to evaluate risk and clinical significance associated with sequence variation in BRCA1 and BRCA2 genes. Hum Mutat 2012;33:2-7.

16 Parsons MT, Tudini E, Li H, Hahnen E, Wappenschmidt B, Feliubadaló L, Aalfs CM, Agata S, Aittomäki K, Alducci E, Alonso-Cerezo MC, Arnold N, Auber B, Austin R, Azzollini J, Balmaña J, Barbieri E, Bartram CR, Blanco A, Blümcke B, Bonache S, Bonanni B, Borg Åke, Bortesi B, Brunet J, Bruzzone C, Bucksch K, Cagnoli G, Caldés T, Caliebe A, Caligo MA, Calvello M, Capone GL, Caputo SM, Carnevali I, Carrasco E, Caux-Moncoutier V, Cavalli P, Cini G, Clarke EM, Concolino P, Cops EJ, Cortesi L, Couch FJ, Darder E, de la Hoya M, Dean M, Debatin I, Del Valle J, Delnatte C, Derive N, Diez O, Ditsch N, Domchek SM, Dutrannoy V, Eccles DM, Ehrencrona H, Enders U, Evans DG, Farra C, Faust U, Felbor U, Feroce I, Fine M, Foulkes WD, Galvao HCR, Gambino G, Gehrig A, Gensini F, Gerdes A-M, Germani A, Giesecke J, Gismondi V, Gómez C, Gómez Garcia EB, González S, Grau E, Grill S, Gross E, Guerrieri-Gonzaga A, Guillaud-Bataille M, Gutiérrez-Enríquez S, Haaf T, Hackmann K, Hansen TVO, Harris M, Hauke J, Heinrich T, Hellebrand H, Herold KN, Honisch E, Horvath J, Houdayer C, Hübbel V, Iglesias S, Izquierdo A, James PA, Janssen LAM, Jeschke U, Kaulfuß S, Keupp K, Kiechle M, Kölbl A, Krieger S, Kruse TA, Kvist A, Lalloo F, Larsen M, Lattimore VL, Lautrup C, Ledig S, Leinert E, Lewis AL, Lim J, Loeffler M, López-Fernández A, LucciCordisco E, Maass N, Manoukian S, Marabelli M, Matricardi L, Meindl A, Michelli RD, Moghadasi S, Moles-Fernández A, Montagna M, Montalban G, Monteiro AN, Montes E, Mori L, Moserle L, Müller CR, Mundhenke C, Naldi N, Nathanson KL, Navarro M, Nevanlinna H, Nichols CB, Niederacher D, Nielsen HR, Ong K-R, Pachter N, Palmero El, Papi L, Pedersen IS, Peissel B, Perez-Segura P, Pfeifer K, Pineda M, Pohl-Rescigno E, Poplawski NK, Porfirio B, Quante AS, Ramser J, Reis RM, Revillion F, Rhiem K, Riboli B, Ritter J, Rivera D, Rofes P, Rump A, Salinas M, Sánchez de Abajo AM, Schmidt G, 
Schoenwiese U, Seggewiß J, Solanes A, Steinemann D, Stiller M, Stoppa-Lyonnet D, Sullivan KJ, Susman R, Sutter C, Tavtigian SV, Teo SH, Teulé A, Thomassen M, Tibiletti MG, Tischkowitz M, Tognazzo S, Toland AE, Tornero E, Törngren T, Torres-Esquius S, Toss A, Trainer AH, Tucker KM, van Asperen CJ, van Mackelenbergh MT, Varesco L, Vargas-Parra G, Varon R, Vega A, Velasco Ángela, Vesper A-S, Viel A, Vreeswijk MPG, Wagner SA, Waha A, Walker LC, Walters RJ, Wang-Gohrke S, Weber BHF, Weichert W, Wieland K, Wiesmüller L, Witzel I, Wöckel A, Woodward ER, Zachariae S, Zampiga V, Zeder-Göß C, Lázaro C, De Nicolo A, Radice P, Engel C, Schmutzler RK, Goldgar DE, Spurdle $A B, K C o n F a b$ Investigators. Large scale multifactorial likelihood quantitative analysis of BRCA1 and BRCA2 variants: an enigma resource to support clinical variant classification. Hum Mutat 2019;40:1557-78.

17 Thompson BA, Spurdle AB, Plazzer J-P, Greenblatt MS, Akagi K, Al-Mulla F, Bapat B, Bernstein I, Capellá G, den Dunnen JT, du Sart D, Fabre A, Farrell MP, Farrington SM, Frayling IM, Frebourg T, Goldgar DE, Heinen CD, Holinski-Feder E, Kohonen-Corish M, Robinson KL, Leung SY, Martins A, Moller P, Morak M, Nystrom M, Peltomaki P, Pineda M, Qi M, Ramesar R, Rasmussen LJ, Royer-Pokora B, Scott RJ, Sijmons R, Tavtigian SV, Tops CM, Weber T, Wijnen J, Woods MO, Macrae F, Genuardi M. Application of a 5 -tiered scheme for standardized classification of 2,360 unique mismatch repair gene variants in the insight locus-specific database. Nat Genet 2014;46:107-15.

18 Richards S, Aziz N, Bale S, Bick D, Das S, Gastier-Foster J, Grody WW, Hegde M, Lyon E, Spector E, Voelkerding K, Rehm HL, ACMG Laboratory Quality Assurance Committee. Standards and guidelines for the interpretation of sequence variants: a joint consensus recommendation of the American College of medical genetics and genomics and the association for molecular pathology. Genet Med 2015;17:405-24.

19 ClinGen variant curation expert panel. ClinGen TP53 expert panel specifications to the ACMG/AMP variant interpretation guidelines version 1, 2019. Available: https:// clinicalgenome.org/site/assets/files/3876/clingen_tp53_acmg_specifications_v1. pdf2019

20 Brnich SE, Abou Tayoun AN, Couch FJ, Cutting GR, Greenblatt MS, Heinen CD, Kanavy DM, Luo X, McNulty SM, Starita LM, Tavtigian SV, Wright MW, Harrison SM, Biesecker LG, Berg JS, Clinical Genome Resource Sequence Variant Interpretation Working Group.
Recommendations for application of the functional evidence PS3/BS3 criterion using the ACMG/AMP sequence variant interpretation framework. Genome Med 2019;12:3.

21 ClinGen variant curation expert panel. ClinGen CDH1 expert panel specifications to the ACMG/AMP variant interpretation guidelines version 2, 2019. Available: https:// clinicalgenome.org/site/assets/files/3982/clingen_cdh1_acmg_specifications_V2.pdf

22 Mester JL, Ghosh R, Pesaran T, Huether R, Karam R, Hruska KS, Costa HA, Lachlan K, Ngeow J, Barnholtz-Sloan J, Sesock K, Hernandez F, Zhang L, Milko L, Plon SE, Hegde $M$, Eng C. Gene-Specific criteria for PTEN variant curation: recommendations from the ClinGen PTEN expert panel. Hum Mutat 2018;39:1581-92.

23 Tavtigian SV, Greenblatt MS, Harrison SM, Nussbaum RL, Prabhu SA, Boucher KM Biesecker LG, ClinGen Sequence Variant Interpretation Working Group (ClinGen SVI). Modeling the ACMG/AMP variant classification guidelines as a Bayesian classification framework. Genet Med 2018;20:1054-60.

24 Ellard S, Baple EL, Berry I, Forrester N, Turnbull C, Owens M, Eccles DM, Abbs S, Scott R, Deans Z, Lester T, Campbell J, Newman W, McMullan D. ACGS best practice guidelines for variant classification in rare disease 2020: Association for Clinical Genomic Science (ACGS), 2020. Available: https://www.acgs.uk.com/quality/bestpractice-guidelines/\#VariantGuidelines

25 Luheshi L, Hall A, Baple E, Ellard S, McMullan D, Raza, S. Variant classication and interpretation workshop report, 2017. Assocation for clinical genomic science (ACGS) and PHG Foundation. Available: https://www.phgfoundation.org/documents/Variant\% 20classification\%20and\%20identification\%20June\%202017.pdf

26 Turnbull C, Scott RH, Thomas E, Jones L, Murugaesu N, Pretty FB, Halai D, Baple E, Craig C, Hamblin A, Henderson S, Patch C, O'Neill A, Devereau A, Smith K, Martin AR, Sosinsky A, McDonagh EM, Sultana R, Mueller M, Smedley D, Toms A, Dinh L, Fowler T, Bale M, Hubbard T, Rendon A, Hill S, Caulfield MJ, 100000 Genomes Project. The 100000 Genomes Project: bringing whole genome sequencing to the NHS. BMJ 2018;361:k1687.

27 NHS Genomic Medicine Service. NHS England, 2019. Available: https://www.england. nhs.uk/genomics/nhs-genomic-med-service/

28 Cox JH. Available: https://www.openpseudonymiser.org/About.aspx 